\title{
Ocean-atmosphere interaction and synoptic weather conditions in association with the two contrasting phases of monsoon during BOBMEX-1999
}

\author{
S P Ghanekar, V R Mujumdar, P Seetaramayya and U V Bhide \\ Indian Institute of Tropical Meteorology, Dr. Homi Bhabha Road, Pashan, Pune 411008.
}

\begin{abstract}
Surface meteorological parameters acquired during the field phase experiment, BOBMEX-99, for the stationary periods (SP I and II) of the ship ORV Sagar Kanya over Bay of Bengal have been analysed. Active and weak monsoon conditions were observed during the first and the second phase of the experiment respectively over India as well as over the stationary ship location. The phase mean sea surface temperature (SST) is found to be the same in both the phases, however large differences have been observed in the phase mean values of wind speed, mean sea level pressure, latent heat and momentum fluxes at air-sea interface. Synoptic scale monsoon disturbances formed only during the period of strong north-south pressure gradient over the Bay region. Events of prominent fall in SST and in the upper $15 \mathrm{~m}$ ocean layer mean temperature and salinity values during typical rainfall events are cited. The impact of monsoon disturbances on ocean-atmosphere interface transfer processes has been investigated.
\end{abstract}

\section{Introduction}

Indian summer monsoon shows distinguished features like active-break phases on intra-seasonal scale which in turn result into the wet and dry spells respectively. Duration of these spells ultimately decides the overall performance of the season. During the months of July and August, these phases are related to the oscillations of the monsoon trough over the Indian region. More frequent cyclogenesis keep the monsoon trough more aligned to its normal position with higher cyclonic vorticity within it and ultimately results in high seasonal rainfall over India (Sikka 1980). During these peak monsoon months, monsoon disturbances generally form at the eastern end of the trough over the head Bay of Bengal and move west-northwestward across it. Sea surface plays an important role in the genesis and intensification of synoptic scale disturbances over oceans. On the other hand, these disturbances have an impact on the oceanic mixed layer, causing changes in the SST. This complex feed back process between the sea surface and the atmospheric disturbances is important in determining the life span of the synoptic scale events (Paul et al 1992). In view of these facts, the present study makes an attempt to analyse the special experimental data of BOBMEX-99 to understand the role of Bay of Bengal in the genesis of monsoon disturbances, their movements and associated airsea interaction processes.

The 'Bay of Bengal Monsoon Experiment' (BOBMEX-99), under the Indian Climate Research Program (ICRP, DST, India) was carried out in two phases viz., phase I: 16th July8th August and phase II: 11th-31st August 1999. The present study is based on the surface marine meteorological observations taken onboard ORV Sagar Kanya during its stationary periods 27th July-5th August (SP I) and 13th-22nd August 1999 (SP II) over north Bay of Bengal at $17.5^{\circ} \mathrm{N}, 89^{\circ} \mathrm{E}$. Three-hourly data of mean sea level pressure (MSLP), wind speed (WS) and direction (WDN), total cloud cover $(\mathrm{N})$, dry bulb

Keywords. BOBMEX-99; Indian summer monsoon; monsoon trough; monsoon disturbances; ocean-atmosphere interaction. 
temperature $\left(\mathrm{T}_{\mathrm{a}}\right)$, dew point temperature $\left(\mathrm{T}_{\mathrm{d}}\right)$, sea surface temperature (SST) and the weather information (ww, $\mathrm{W}_{1}$ and $\mathrm{W}_{2}$ ) observed onboard ORV Sagar Kanya are analysed. In addition to these, the temperature and salinity data, acquired using CTD operations, for the upper $15 \mathrm{~m}$ layer of the ocean are also used. The day-to-day monsoon conditions during BOBMEX-99 are studied using Daily All India Weather Summaries and Indian Daily Weather Reports (IDWR) published by India Meteorological Department (IMD) and the surface (03 UTC) and upper air (00 UTC) weather charts prepared at Weather Central, IMD, Pune.

\section{Monsoon performance over India and synoptic situation over Bay of Bengal}

Figure 1(a) shows the temporal variations of daily percentage departures of all India monsoon rainfall (based on rainfall departure of all reporting stations from their daily normals) for the phase I and phase II of the experiment. The synoptic scale disturbances viz., well marked low pressure areas (WL1, WL2 and WL3), a deep depression (DD), a depression (D), an upper-air cyclonic circulation (CC) and low pressure areas (L1 and L2) which formed during this period are shown at the top of figure 1(c). The duration of these events is marked by a dotted line, from their respective formation till the system is observed as a low pressure area on the surface chart. The period when they attained their maximum intensity is shown by a thick line. WL2 formed over the land near $26^{\circ} \mathrm{N}, 80^{\circ} \mathrm{E}$. All other well-marked disturbances initially formed over Head Bay region and moved across the country. An upper-air cyclonic circulation (CC) that prevailed over the Bay region on 15th August and could not intensify further but influenced the weather over Sagar Kanya, which subsequently moved inland (15th to 19th August) is shown in the figure. Except this system, other upper air systems are not discussed in the present analysis.

High values of the positive departures of daily rainfall ranging between 40 and $60 \%$ of the normal are observed during 16th-22nd July. The rainfall remained slightly above normal on 27th July, 2nd August and 6th-7th August (figure 1a). These rainfall events correspond to the presence of monsoon disturbances WL1, DD, WL3 and D which formed over Bay of Bengal and moved westward across the monsoon trough. This indicates an active monsoon condition during phase I. Contrary to this, during phase II, large negative departures in rainfall are seen up to 25th August except the slightly above-normal rainfall departure on 10th
August which corresponds to the presence of the remnant of the disturbance (D) of the previous phase. The long epoch of below-normal rainfall and absence of synoptic scale disturbances indicate weak monsoon conditions in phase II. The positive departures of rainfall on 26th and 30th August occurred under the influence of two low pressure systems (L1 and L2). L1, especially formed very much southward in location and its center was observed very near to the east coast of India. These systems have formed at the end of the experiment and outside the stationary period of Sagar Kanya.

Paul et al (1990) have attributed the performance of the monsoon to the variability of zonal index i.e., the surface pressure difference between Thiruvananthapuram and Nagpur, over Indian land region. The better performance of the monsoon is linked with the high values of zonal index which is seen to be accompanied by the strong lowlevel westerlies over the Indian peninsula producing cyclonic wind shear and in turn give rise to the synoptic scale weather events over India. During July and August, synoptic scale disturbances usually form over north Bay and contribute to the performance of the monsoon. In the present analysis, the role of pressure gradient in formation of such disturbances is studied by estimating an oceanic zonal index (OZI) over the region of Bay of Bengal. The OZI is computed as the surface pressure gradient along $89^{\circ} \mathrm{E}$, between latitudes $5^{\circ} \mathrm{N}$ and $18^{\circ} \mathrm{N}$ estimated from the $03 \mathrm{UTC}$, surface charts. Figure 1(b) shows the variation of the OZI over the Bay of Bengal from 16th July to 31st August 99. It is seen that the OZI fluctuated around a mean value of about $9 \mathrm{hPa}$ in phase $\mathrm{I}$ and around $6 \mathrm{hPa}$ in phase II. Very high pressure gradients $(>10 \mathrm{hPa})$ are observed on 25th July, 1st2nd August and 4th-8th August during phase I and on 26th August during phase II. Such increase in the index is observed to be followed by formation of intense low pressure systems over the Bay region. Like the zonal index over India, OZI would also be related to the strong low level zonal flow and increase in cyclonic vorticity, following which, development of disturbances is observed over the Bay of Bengal.

Figure 1(c) presents daily latitudinal position of the axis of the monsoon trough deduced from $03 \mathrm{UTC}$ surface charts (IDWR) at $89^{\circ} \mathrm{E}$ over the Bay region. The normal position of axis of the monsoon trough during July and August, at $89^{\circ} \mathrm{E}$ lies near $22^{\circ} \mathrm{N}$ which is northward of the stationary ship location by $4.5^{\circ}$ latitudes. It is interesting to note from the figure that the axis is located slightly to the south of its normal position on most of the days during phase I. The trough is found to be located further southward prior to the formation 

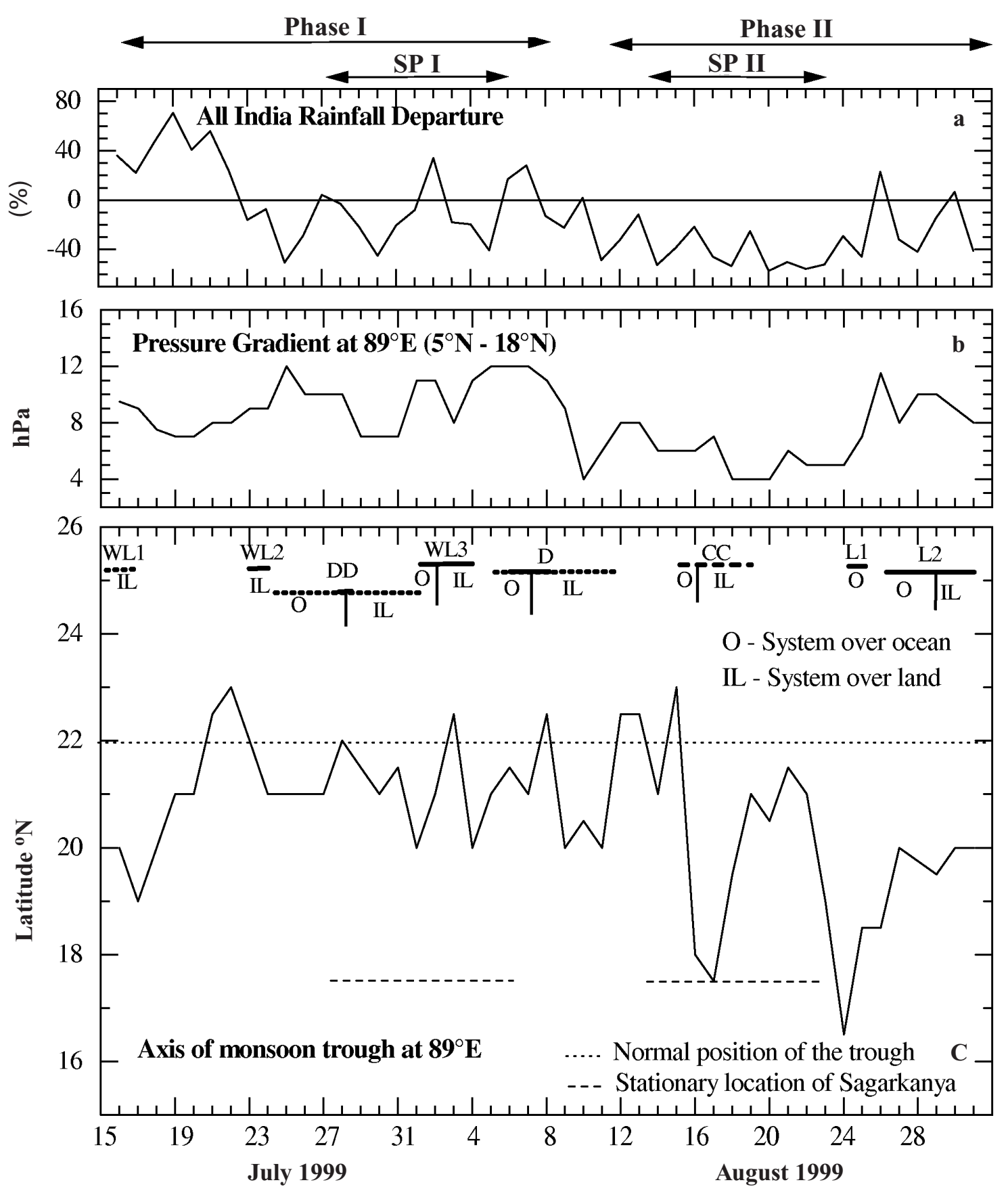

Figure 1. Daily variation of (a) Percentage departure of all India rainfall from daily weather summaries, (b) Oceanic zonal index $\left(5^{\circ}-18^{\circ} \mathrm{N}\right)$ along $89^{\circ} \mathrm{E}$ and (c) Daily latitudinal position of the axis of monsoon trough deduced from the $03 \mathrm{UTC}$ surface charts, along $89^{\circ} \mathrm{E}$ during the period of the experiment (16th July - 31st August).

of each low pressure system over north Bay. During the stationary period of Sagar Kanya, three intense low pressure systems viz., (1) Deep Depression (DD: 27th-28th July), (2) Well-marked Low (WL3: 2nd-4th August) and (3) Depression (D: 6th-8th August) formed at the eastern end of the monsoon trough over the head Bay. These systems initially developed as a low pressure area with surface central positions around (1) $21^{\circ} \mathrm{N}, 89^{\circ} \mathrm{E}$ on 25th July, (2) $20^{\circ} \mathrm{N}, 88^{\circ} \mathrm{E}$ on 1st August and (3) $21^{\circ} \mathrm{N}, 89^{\circ} \mathrm{E}$ on 5 th August respectively. On the day when they reached peak intensity their corresponding centres were located around $(1) 23^{\circ} \mathrm{N}, 86.5^{\circ} \mathrm{E}$, (2) $21^{\circ} \mathrm{N}, 88.5^{\circ} \mathrm{E}$ and (3) $22.5^{\circ} \mathrm{N}, 87.5^{\circ} \mathrm{E}$. With the passage of these disturbances west-northwestward over land, the trough axis at $89^{\circ} \mathrm{E}$, subsequently moved towards north and restored to its normal position. The variation of monsoon trough position is remarkable during phase II. The axis at $89^{\circ} \mathrm{E}$ initially located north of its normal position around 12th - 14th August. During subsequent periods the eastern end of the trough branched 
into two parts, one running over the Indian land north of the normal position and the other over the Bay region (Ghanekar et al 2001). In the present study, however, only the fluctuation of the oceanic branch is discussed. Around 16th August the trough axis moved over west central Bay as a weak extension when the pressure gradient is found to be very low (figure 1b). Around 15th19th August of phase II, abrupt fluctuations in the position of the trough axis are observed. During these days a cyclonic circulation (CC) formed in the mid-troposphere over the Bay region and moved inland without descending down to form a marked disturbance at surface. The axis showed its passage across the ship location on 17th August only. Subsequent to this, L1 is formed at a still southward location and this is reflected in the most southerly position of the trough on 24th August between $16^{\circ}$ and $17^{\circ} \mathrm{N}$. With the formation and the movement of L2, the trough moved northward to its near normal location by 25th August.

Thus in phase I, events of the southward shift of the axis of the monsoon trough over Bay of Bengal from its normal position and high OZI $(>10 \mathrm{hPa}$, figure 1b) are followed by the formation of intense low pressure systems such as DD, WL and D over the Head Bay. In phase II the values of OZI are very low $(<6 \mathrm{hPa})$ throughout the stationary period of Sagar Kanya from 13th to 22nd August. The eastern end of the trough was branched on few days with the continental branch running north of the normal position while the oceanic branch was found to extend very much southward as compared to its normal position. The southward shift around 24th August when L1 and L2 formed is remarkable and similar to what is observed in break situations over India. These developments indicate that the atmospheric conditions over north Bay of Bengal became unfavorable for cyclogenesis. Such observations suggest that a north-south pressure gradient OZI $>10 \mathrm{hPa}$, which is also related to the near normal position of the trough as observed in phase I of the experiment, is an important factor for development of cyclogenesis over north Bay. The cyclogenesis is seen to be inhibited/reduced during the period of weak north-south pressure gradient and during extension of the trough axis far southward over west central Bay. Thus, India experienced active and weak monsoon conditions during phase I and phase II respectively. During these periods, contrast is observed in cyclogenesis over Bay of Bengal also. Hence the analysis of various surface parameters, fluxes at air-sea interface and the mean upper ocean temperature and salinity observed during the stationary period of Sagar Kanya is carried out and studied in relation to these monsoon conditions.

\section{Temporal variations of the surface meteorological parameters at stationary ship position}

Figure 2 shows the time series of three hourly surface meteorological parameters viz., N, WS, MSLP, SST, $T_{a}$ and $T_{d}$ during SP I and SP II. The events of rainfall are qualitatively shown in figure 2(a) in the form of a histogram. A column of length of one unit signifies the occurrence of rainfall over the ship. A column of two units indicates rainfall with moderate intensity and of three units indicates heavy shower of rain. The column of length four units indicates the occurrence of rainfall along with a thunderstorm event.

During SP I, all the meteorological parameters near Sagar Kanya were mainly influenced by the formation and movement of three well-marked systems. During the formative periods of the WL3 and $\mathrm{D}$, the sky remained overcast with occasional spells of rainfall from 30th July to 1st August and 3rd to 5th August respectively. The wind speed (WS) exceeded $10 \mathrm{mps}$ (figure $2 \mathrm{~b}$ ) from 27th to 29th July and 1st to 6th August when the ship was located to the south of the axis of monsoon trough during the formation and movement of the disturbances. On 30th and 31st July, WS is observed to be low, about $7 \mathrm{mps}$. This is the period when the axis of the monsoon trough is observed to be moving towards the ship. The WS shows the phase maximum during the passage of $\mathrm{D}$ (figure $2 \mathrm{~b}$ ). The daily variation of MSLP has shown three significant minima (figure 2c) reaching $999 \mathrm{hPa}$ or less on 27th July, 1st August and on 5th August. Subsequent to these occasions, three disturbances viz., DD, WL3 and D respectively formed over Bay of Bengal. All these systems have formed over the warm ocean surface with SSTs greater than $28.4^{\circ} \mathrm{C}$ which is in corroboration with the observation of Sarma et al (1997). MSLP has shown systematic increase subsequent to the movement of these monsoon disturbances from the oceanic region to the Indian continental region. The fluctuations of the $T_{a}$ and $T_{d}$ (figure 2e) have in general shown variations similar to those of SST (figure 2d).

During SP II, no system is found to develop over the Head Bay region. An upper air cyclonic circulation is noticed from 15th-19th August. However, the day-to-day fluctuation in the position of monsoon trough (figure 1c) over the Head Bay region has largely affected the weather conditions at the stationary ship location. Overcast sky condition and occasions of rainfall events are observed from 13th to 16th August (figure 2a). Strong WS exceeding $10 \mathrm{mps}$ prevailed up to 15th August. This is the time when an upper air cyclonic circulation was observed over the Head Bay. This event is followed 
SP I

SP II
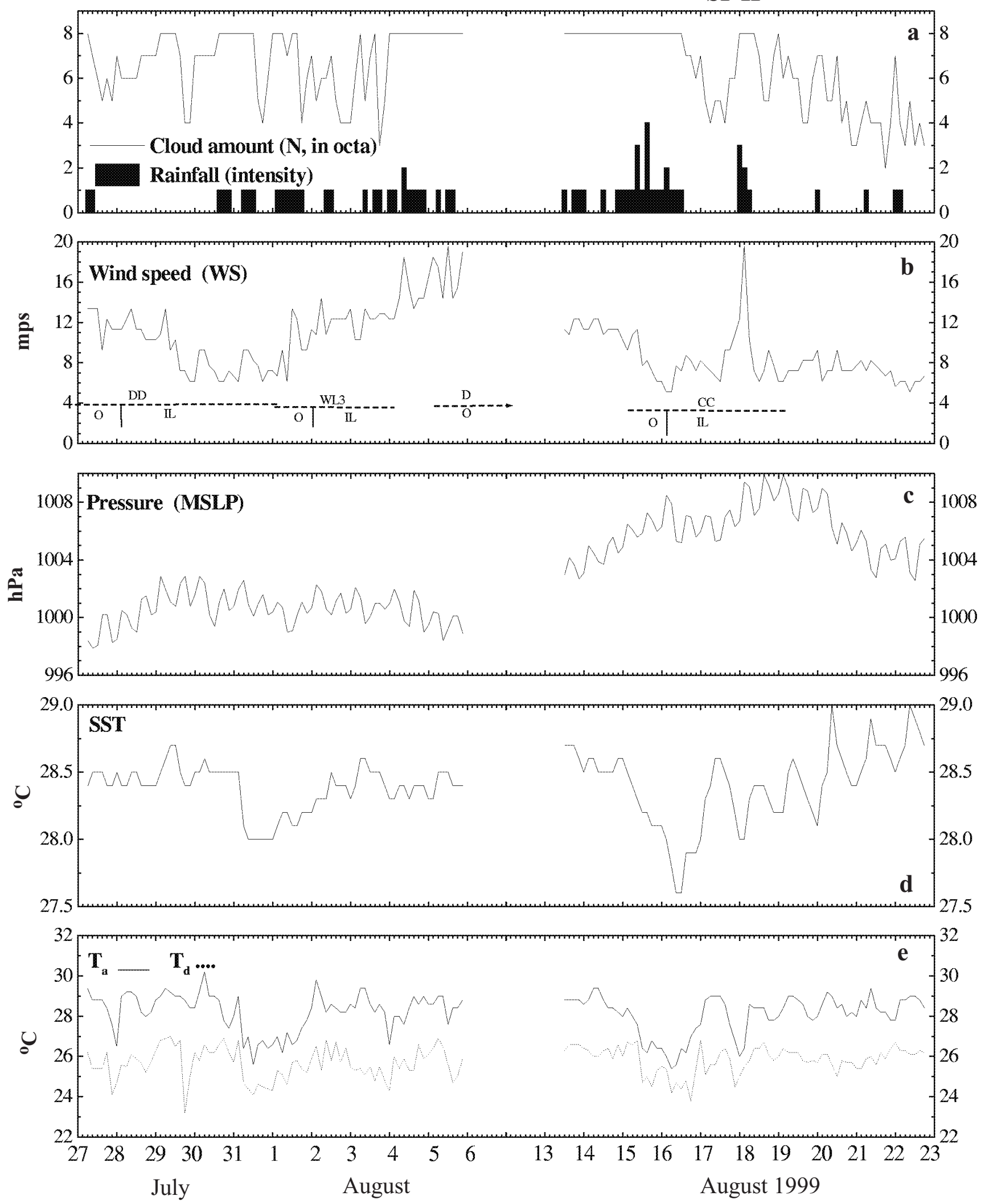

Figure 2. Time-series of surface meteorological parameters viz. : (a) Total cloud amount (N, solid line) and rainfall events (Histogram), (b) Surface wind speed (WS), (c) Mean sea level pressure (MSLP), (d) Sea surface temperature (SST) and (e) Air ( $\mathrm{T}_{\mathrm{a}}$, solid line) and dew-point $\left(\mathrm{T}_{\mathrm{d}}\right.$, dotted line) temperatures during the stationary periods (SP I and SP II) of Sagar kanya over Bay of Bengal. 
Table 1. Phase mean values of surface meteorological parameters during the stationary periods (SP I and SP II) of Sagar Kanya during BOBMEX-1999.

\begin{tabular}{lc|rrc|rrr}
\hline & & \multicolumn{3}{|c|}{ SP I } & \multicolumn{3}{c}{ SP II } \\
\cline { 3 - 8 } Sr. no. & Parameter & Min. & Max. & \multicolumn{1}{c|}{ Mean } & Min. & Max. & Mean \\
\hline 1 & MSLP (hPa) & 997.9 & 1002.9 & $\mathbf{1 0 0 0 . 6}$ & 1002.6 & 1009.9 & $\mathbf{1 0 0 6 . 1}$ \\
2 & WS (mps) & 6.2 & 19.6 & $\mathbf{1 1 . 3}$ & 5.1 & 19.6 & $\mathbf{8 . 4}$ \\
3 & SST $\left({ }^{\circ} \mathrm{C}\right)$ & 28.0 & 28.7 & $\mathbf{2 8 . 4}$ & 27.6 & 29.0 & $\mathbf{2 8 . 4}$ \\
\hline
\end{tabular}

Table 2. Phase mean values of heat, moisture and momentum fluxes observed at the ocean-atmosphere interface during the stationary periods (SP I and SP II) of Sagar Kanya during BOBMEX-1999.

\begin{tabular}{lc|ccc|ccc}
\hline & & \multicolumn{3}{|c|}{ SP I } & \multicolumn{3}{c}{ SP II } \\
\cline { 3 - 8 } Sr. no. & Parameter & Min. & Max. & Mean & Min. & Max. & Mean \\
\hline 1 & $Q_{H}\left(\mathrm{Wm}^{-2}\right)$ & -13.7 & 32.7 & $\mathbf{4 . 4}$ & -8.8 & 44.1 & $\mathbf{6 . 5}$ \\
2 & $Q_{E}\left(\mathrm{Wm}^{-2}\right)$ & 44.0 & 324.0 & $\mathbf{1 6 9 . 8}$ & 38.0 & 262.0 & $\mathbf{1 2 1 . 6}$ \\
3 & $\mathrm{BR}$ & -0.151 & 0.189 & $\mathbf{0 . 0 2 4}$ & -0.054 & 0.183 & $\mathbf{0 . 0 5 3}$ \\
4 & $\tau\left(\mathrm{Nm}^{-2}\right)$ & 0.086 & 0.853 & $\mathbf{0 . 3 0 9}$ & 0.061 & 0.852 & $\mathbf{0 . 1 7 3}$ \\
\hline
\end{tabular}

by a gradual decrease in the $\mathrm{N}$, reducing to about 4 octa by the end of the phase (figure 2a) and WS further fluctuated around 8 mps (figure $2 \mathrm{~b}$ ) during the rest of the period. In the early hours of 18th August, under overcast sky condition, rain showers, with moderate to heavy intensity are observed. Abrupt increase in the WS reaching as high as about $19 \mathrm{mps}$ is also observed during these hours. This has occurred in the absence of a well-marked synoptic scale disturbance over the region. Such gusty winds are likely to be associated with the convective downdrafts enhancing the surface winds. These observations suggest the presence of a meso-scale system in the vicinity of the ship. An abrupt south to north movement of the monsoon trough across the ship around this day (figure 1c) supports the possibility of such a meso-scale event.

A fall in SST, of about $1^{\circ} \mathrm{C}$ is observed during $00 \mathrm{UTC}$ of 15 th to $12 \mathrm{UTC}$ of 16th August (figure 1d), which is a remarkable feature. A sudden increase in the MSLP of about $3.5 \mathrm{hPa}$ from 00 UTC of 15th August to 03 UTC of 16th August and of about $4 \mathrm{hPa}$ during $12 \mathrm{UTC}$ of $17 \mathrm{th}$ to 03 UTC of 18th August at the ship can be attributed to colder SST in SP II. Shukla (1975) has also attributed the colder SST anomaly to an increase in the surface pressure and a consequent reduction in the evaporation. During the later part of SP II, from 16 UTC of 18th August onwards, the SST has shown a gradual increase in the values up to the end of SP II. The diurnal variation is also large during this period. This must be the consequence of an increase in the incoming solar radiation at the sea surface due to the observed reduction of $\mathrm{N}$ and it is consistent with the earlier observations by Rao et al (1985). During this period a decrease in MSLP is also noticed.

The phase mean values of selected surface marine meteorological parameters during SP I and SP II are tabulated in table 1 . The table gives the information of WS, MSLP and SST. The phase mean values of WS indicate weakening of wind from SP I to SP II. The climatological value of MSLP around the ship location is 1001.2 for July and 1003.0 for August (Hastenrath and Lamb 1979). The phase mean MSLP in SP I (SP II) is lower (remarkably higher) than the climatological values for the respective months. This is a remarkable contrasting feature of the experiment and it is reflected in the monsoon activity over India. The increased MSLP near the ship location during SP II has resulted into weak north-south pressure gradient over the region and is confirmed through weakening of the winds during this phase (figure $1 \mathrm{~b}$ ). The phase mean value of SST is almost tallying with the climatological value of $28.4^{\circ} \mathrm{C}$ in SP I while that is higher than the climatological value of $28.1^{\circ} \mathrm{C}$ (Hastenrath and Lamb 1979) in SP II. Table 1 clearly depicts contrast between these two periods. The parameters also show more fluctuations in SP II than in SP I (figure 2).

Thus in spite of favorable support of ocean in terms of SST during both the phases (with phase mean as $28.4^{\circ} \mathrm{C}$ for both phases), the formation of low pressure systems is realised only during SP I in the presence of other favorable atmospheric conditions. Weak pressure gradient and the orientation of the monsoon trough far south to its normal position over the Bay of Bengal, made conditions unfavorable for cyclogenesis during SP II over the Bay 
region. It is well-known that the SST plays a dominant role in determining the variability in convection. The inclination towards convection increases over the regions of warm waters of the oceans. Gadgil et al (1984) have observed a threshold value of $28^{\circ} \mathrm{C}$, for an organised deep convection to occur. During both periods, SST is not found far off from the threshold. It needs to be noted that a decrease in SST on 15th August below $28^{\circ} \mathrm{C}$ was noticed for a period of one day. Following this occasion, $\mathrm{N}$, rainfall, WS showed considerable decrease while MSLP, SST showed increase during the rest of the period of SP II and undisturbed conditions developed at Sagar Kanya while weak monsoon conditions developed over India. Thus, contrasting monsoon conditions during SP I and SP II are observed over the north Bay region similar to that over India.

\section{Temporal variations of the surface fluxes at stationary ship position}

The air-sea transfer processes over the oceanic region near the ship location during SP I and SP II have been examined by computing the sensible heat, latent heat and momentum fluxes, utilizing the bulk aerodynamical formulae as suggested by Stevenson (1982). Ghanekar et al (2001) have earlier computed the above fluxes for phase II of the same experiment by applying a correction to the sensible heat by adding a part of latent heat to it. In the present study, such correction to the sensible heat flux has been omitted and the coefficients of specific heat and latent heat of evaporation are assumed to be constant following Anderson and Smith (1981). Figure 3 shows the time series of the surface fluxes of sensible heat $\left(\mathrm{Q}_{\mathrm{H}}\right)$, latent heat $\left(\mathrm{Q}_{\mathrm{E}}\right)$, momentum flux $(\tau)$ and the Bowen Ratio $\left(B R=Q_{H} / Q_{E}\right)$ during SP I and SP II.

During SP I, high values of heat and momentum fluxes are observed during strong wind conditions in association with the prevailing disturbed weather conditions due to synoptic weather systems. This observation is consistent with the results from the earlier studies (Bhide et al 1986; Sam et al 2000; Murty et al 2000 etc.). Particularly, very high values of $\mathrm{Q}_{\mathrm{E}}\left(>250 \mathrm{Wm}^{-2}\right), \mathrm{Q}_{\mathrm{H}}\left(>20 \mathrm{Wm}^{-2}\right)$ and $\tau\left(>0.6 \mathrm{Nm}^{-2}\right)$ are observed at $09 \mathrm{UTC}$ of 4 th August and 12 UTC of 5th August during the formative period of the depression (D) in SP I. These are also accompanied with overcast sky and rain showers (figure 2a). The transfer of $\tau$ across the airsea interface decreased from $0.4 \mathrm{Nm}^{-2}$ to $0.1 \mathrm{Nm}^{-2}$ on 29 th July. It is less than $0.2 \mathrm{Nm}^{-2}$ from 00 UTC of 30th July to 09 UTC of 1st August. These low values of $\tau$ observed during the period of low wind speeds (figure $2 \mathrm{~b}$ ), supports the earlier observation (of WS and the trough position on these days) that the ship was in the vicinity of the trough. The $\tau$ further increased from $0.1 \mathrm{Nm}^{-2}$ to $0.8 \mathrm{Nm}^{-2}$ from 1st August to 5th August during the disturbed conditions. In SP II, an isolated peak in all the fluxes is observed at 03 UTC 18th August due to high WS (figure 2b) associated with the mesoscale system near the ship. Overcast sky with rain showers are also noticed during these hours. The other prominent peaks in $\mathrm{Q}_{\mathrm{E}}$ and $\mathrm{Q}_{\mathrm{H}}$ at $21 \mathrm{UTC}$ of 27 th July to 00 UTC of 28th July, 18 UTC of 29 th July and at 18 UTC of 16th August are associated with low wind speeds. These events occurred due to night-time fall (noctural cooling) in $\mathrm{T}_{\mathrm{a}}$ with prominent fall in $\mathrm{T}_{\mathrm{d}}$ (figure $2 \mathrm{e}$ ) and are associated with reduction in cloud cover (figure 2a). High values of BR (around 0.1 units or more) are noticed at $00 \mathrm{UTC}$ of 28th July and during $18 \mathrm{UTC}$ of 30th July to 18 UTC of 2nd August (except a fall at 03 UTC of 31st July) in SP I. During SP II, high values of BR are observed between 09 UTC of 15th August and 00 UTC of 17th August and during $18 \mathrm{UTC}$ of 17th August to 03 UTC of 18th August. The reason for these high $\mathrm{BR}$ values is due to relatively larger $\mathrm{Q}_{\mathrm{H}}$ values than that of $\mathrm{Q}_{\mathrm{E}}$ values. This has happened during the occasions of a gradual fall in $T_{a}$ and $T_{d}$, and a decrease in the difference between the specific humidities observed at sea surface and deck level. At the same time it is seen that the fall in SST and WS (excepting the last event) also seems to have contributed to high BR values. During these typical events, the fall in the $\mathrm{T}_{\mathrm{a}}$ and SST is due to the cooling in association with rainfall events over the stationary location of Sagar Kanya.

The mean quantities such as fluxes of heat and momentum at air-sea interface and their extremes are given in table 2. The table clearly depicts stronger $\mathrm{Q}_{\mathrm{E}}$ and $\tau$ during SP I as compared to SP II. It is also seen from figure $3(\mathrm{~b})$ that on many occasions $\mathrm{Q}_{\mathrm{E}}$ are greater than $150 \mathrm{Wm}^{-2}$ in SP I while the reverse is noticed during SP II. This suggests more favorable conditions for air-sea interaction processes during the first phase as compared to the second phase. The mean $\mathrm{Q}_{\mathrm{H}}$ and $\mathrm{BR}$ are slightly higher in SP II than in SP I. Two major rainfall events of SP II have contributed to such high values.

\section{SST, upper ocean layer mean temperature and salinity during typical weather events}

Three typical events of fall in the SST values viz., (1) $\sim 0.5^{\circ} \mathrm{C}$ from $03-09$ UTC of 31st July during 

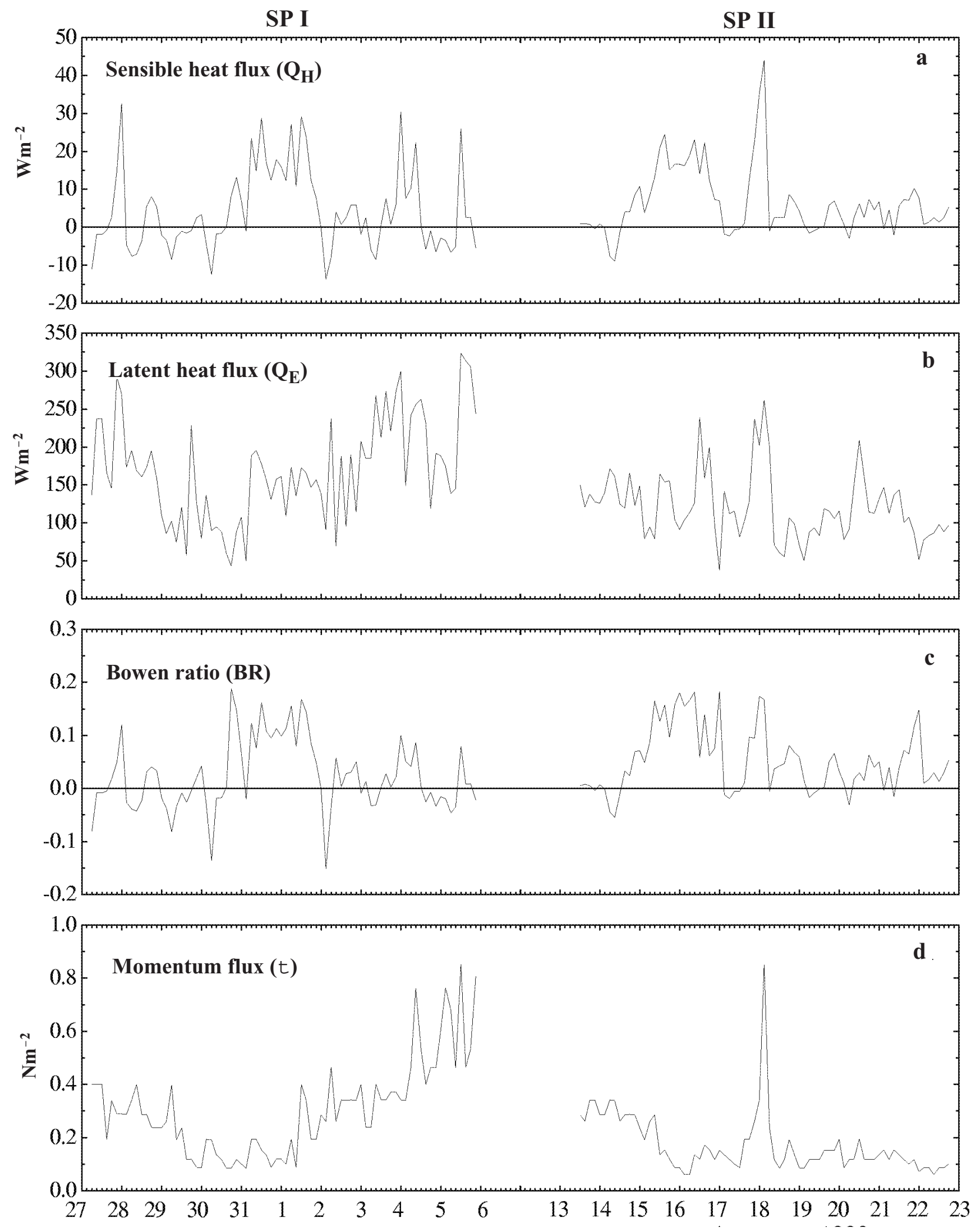

July August

August 1999

Figure 3. Time-series of surface fluxes viz. : (a) Sensible heat flux $\left(\mathrm{Q}_{\mathrm{H}}\right)$, (b) Latent heat flux $\left(\mathrm{Q}_{\mathrm{E}}\right)$, (c) Bowen Ratio (BR) and (d) Momentum flux $(\tau)$ during the stationary periods (SP I and SP II) of Sagar kanya over the Bay of Bengal. 
SP I, (2) $\sim 1{ }^{\circ} \mathrm{C}$ from $00 \mathrm{UTC}$ of 15 th to $12 \mathrm{UTC}$ of 16 th August during SP II, and $(3) \sim 0.6^{\circ} \mathrm{C}$ during 12 UTC of 17th to 00 UTC of 18th August in SP II are observed during the period of experiment. These events will be referred to as S1, S2 and S3 in subsequent discussions. Subsequent to $\mathrm{S} 1$ and S2 the SST values have reduced to $\sim 28^{\circ} \mathrm{C}$ from 09 UTC of 31st July, well below $28^{\circ} \mathrm{C}$ from 03 UTC of 16th August, persisting so for a day and then attaining the minimum of SP I and SP II respectively. Subsequent to S3, the SST have reduced to $\sim 28^{\circ} \mathrm{C}$ between 00 and 03 UTC of 18 th August. Persistence of low SST during S3 is observed for a shorter duration as compared to other two events. Rainfall events under overcast cloudy conditions occurred over the ship (figure 2a) during these events. Considerable decrease in $T_{a}$ and $T_{d}$ (figure $2 \mathrm{e}$ ) with high values of $\mathrm{Q}_{\mathrm{H}}$ and $\mathrm{BR}$ (figure $3 \mathrm{a}$ and $3 \mathrm{c}$ ) are also observed during these periods. S1 is observed prior to the formation of the WL3 of SP I when the DD moved over the Indian continent while S2 is that when the CC of SP II moved from the oceanic region to Indian continent. The fall in SST is usually noticed in association with the strong wind conditions. In the events, S1 and S2, fall was observed during the periods of low winds. This is a remarkable feature. However, S3 is associated with a meso-scale activity in association with the abrupt movement of the monsoon trough across the ship and during this event winds were gusty and heavy showers of rain were observed.

The changes in the uppermost layer of the ocean in relation to the weather events are investigated by analysing the upper $15 \mathrm{~m}$ ocean layer average temperature and similarly averaged salinity data during SP I and SP II. The average values of layer mean $(15 \mathrm{~m})$ temperature and the sea surface temperatures (SST) for the entire duration of the experiment are found to be $28.44^{\circ} \mathrm{C}$ and $28.4^{\circ} \mathrm{C}$ respectively. Figure 4 presents the timeseries of mean salinity (SL, line with symbol-dot), temperature anomaly (TAN, solid line) and the SST anomaly (SAN, dotted line) during SP I and SP II. In general the SAN shows a diurnal variation with high values around 12 UTC and lower values around 03 UTC of the day. In SP I, the TAN shows an increasing trend from 28th July reaching to a maximum value on 29th July. The SAN shows an increase on 29th July while the SL initially does not show much change and starts decreasing from 21 UTC of 28th July. All the parameters have shown a decreasing trend from 29th July with some fluctuations in between. A steep fall in SAN from early hours of 31st July and in TAN and SL from 06 UTC of 31st July to 03 UTC of 2nd August is remarkable and is observed around S1. TAN and SAN show a rapid increase from
03 UTC on 2nd August. After 3rd August they show small fluctuations till the end of SP I. SL has shown a slow increase from 21 UTC of 3 rd August and a rapid increase on 5th August up to the end of SP I. During SP II, the salinity (SL) shows an increasing trend up to 15th August from initial low values while high values of TAN and SAN are observed up to 14th August. A rapid decrease in SAN and TAN is observed from early hours of 15th August. A simultaneous distinct fall in all the three parameters is observed during 00 UTC to 09 UTC of 16th August which is observed to be around the period of S2. The lowest value of SAN is observed at 15 UTC of 16 th August while TAN and SL are found to be lowest at 18 UTC. All the parameters showed a steady increase following which again a simultaneous fall is observed from the late hours of 17th August attaining the low values at 03 UTC in SAN and at 06 UTC in TAN and SL on 18th August. This fall is observed around the period of S3. After this event all the parameters show large diurnal variation with an increasing trend of SAN and TAN till 21st August.

The simultaneous fall in TAN and SL around the events S1, S2 and S3 are in association with the rainfall events due to synoptic/meso-scale activity over the area. The fall in SL values during these periods thus indicates the incursion of fresh water due to rainfall events. The lowest values of TAN and SL during these events are observed with a lag of few hours after the lowest value of SAN. This might be due to the time taken for the mixing of cold fresh water in this ocean layer. The overall decrease in SL from 29th July up to 3rd August and a gradual increase from 13th to 21st August need to be studied in detail. The increase of the SAN and TAN and their large diurnal variations during the later part of SP II from 19th August seems to be due to increased incoming solar radiation on account of a sizable reduction in the total cloud cover (figure 2a).

It is well known that, the uppermost layer of the ocean traps the heat, freshwater and momentum fluxes near the surface, retaining a memory of the fluxes until a wind event large enough to erode the stratification occurs (Flamlent and Sawyer 1995). In the present analysis the events S1 in SP I and S2 in SP II are the prominent events during which relatively lower WS and prolong rainfall events are noticed near the ship location which led to the reduction in the $\mathrm{T}_{\mathrm{a}}, \mathrm{T}_{\mathrm{d}}$ and SST values. During these events, the monsoon trough moved southward towards the ship while during S3 in SP II, the trough was already located southward near the ship location. Flamlent and Sawyer (1995) have also cited a five fold increase in $\mathrm{Q}_{\mathrm{H}}$ and the $\mathrm{BR}$ due to the fresh 


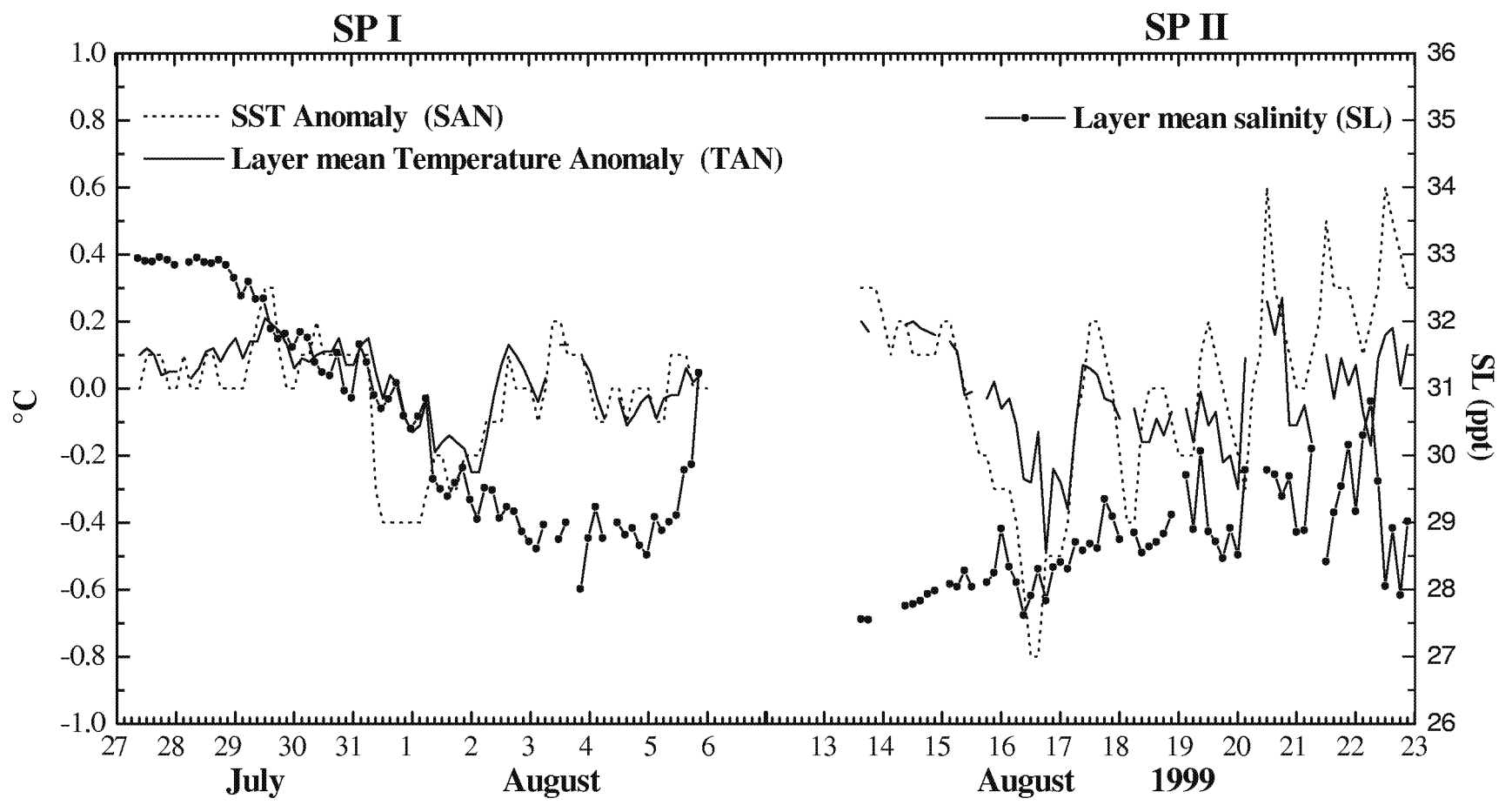

Figure 4. Time-series of sea surface temperature anomaly (SAN, dotted line) the upper $15 \mathrm{~m}$ layer mean temperature anomaly (TAN, solid line) and salinity (SL, solid line with symbol: dot) during the stationary periods (SP I and SP II) of Sagar Kanya over the Bay of Bengal.

water incursion during intense events of rainfall occurred during a transit through ITCZ over the region of tropical Pacific Ocean. An increase in $\mathrm{Q}_{\mathrm{H}}$ and BR noticed during the above events of BOBMEX-99, in association with the prevailing weather disturbances within the ITCZ over Bay of Bengal is similar to that observed over the Pacific Ocean. Such reduction in SST values, observed during typical rainfall events, below the threshold required for convection might lead to stable conditions over the region. During the later period of SP II (17th to 22nd August), all the fluxes show very low values and signify very weak energy transfer processes during the period except a sudden increase in the values at 03 UTC of 18th August due to gusty winds. After the event of S1 in SP $\mathrm{I}$, the moisture transport is reduced while $\mathrm{BR}$ is increased. Subsequent to this, a weaker system such as WL3 developed. The sustained increase in the moisture and momentum fluxes in association with WL3 probably helped the development of the depression (D) on 6th August. But during SP II, initial low values of $\mathrm{Q}_{\mathrm{H}}, \mathrm{Q}_{\mathrm{E}}$ and $\tau$ reduced further when the cyclonic circulation (CC) moved away on 16th August. In such conditions, the event S2 deteriorated the conditions through reduced transports and affected cyclogenesis and led to weak monsoon conditions. These aspects of ocean-atmosphere interaction processes need further investigation.

\section{Conclusions}

Analysis of surface marine meteorological parameters taken onboard ORV Sagar Kanya during SP I and SP II and the synoptic weather conditions observed over the Indian region during the two phases of BOBMEX-99 have revealed that active monsoon conditions prevailed during the first phase while monsoon was weak during the second phase over the Indian region as well as near the stationary position of the ship over the Bay of Bengal. The surface pressure gradient is observed to be strong in SP I while weak in SP II over the Bay region. The phase mean SST during both the stationary periods is observed to be favourable for convection and cyclogenesis. However, the atmospheric conditions such as northsouth pressure gradient have largely contributed in weakening of the monsoon activity in SP II. At the air-sea interface, during SP I, the transfer of heat energy is seen to be dominated by the latent heat flux during epochs of stronger wind speed and rainfall in association with the prevailing disturbances. Two prolonged rainfall events, one during SP I and the other during SP II with overcast sky conditions showed considerable decrease in SST of about $0.5^{\circ} \mathrm{C}$ and $1^{\circ} \mathrm{C}$ respectively. The decrease in sea surface temperature is due to incursion of fresh water to the sea surface in the rainfall events. The sizable decrease $\left(\right.$ of $\left.1^{\circ}\right)$ in SST around 
16th August has influenced the heat and moisture transfer processes at air-sea interface. Subsequent to this event, cyclogenesis over the Bay of Bengal is observed to be reduced and led to weak monsoon conditions over India. These oceanatmosphere interaction processes need further study.

\section{Acknowledgements}

The authors wish to thank Dr. G B Pant, Director, IITM, Pune, for encouragement and Dr. S S Singh, Head, FRD, for his keen interest. Acknowledgments are also due to the Department of Science and Technology, National Institute of Oceanography and India Meteorological Department for data support.

\section{References}

Anderson R J and Smith S D 1981 Evaporation coefficient for the sea surface from eddy flux measurements; J. Geophys.Res. 86, C1 449

Bhide U V, Nagar S G, Mahajan P N and Sikka D R 1986 Fluxes of sensible and latent heat at the air-sea interface over the equatorial Arabian Sea during MONEX-79; Curr. Sci. 55, 15 699-701

Flament P and Sawyer M 1995 Observations of the effect of rain temperature on the surface heat flux in the inter tropical convergence zone; J. Phys. Oceanogr. 25 413-419

Gadgil S, Joseph P V and Joshi N V 1984 Ocean-atmosphere coupling over monsoon regions; Nature 312 141-143

Ghanekar S P, Mujumdar V R, Seetaramayya P and Bhide U V 2001 Variations of surface fluxes and meteorological parameters during the field phase experiment BOBMEX1999 in relation to the prevailing monsoon conditions; Proceedings of TROPMET 2000, National Symposium on Tropical Meteorology, Cochin University of Science and Technology, Kochi, February 2001, 390-395
Hastenrath and Lamb 1979 Climate atlas of the Indian Ocean, Part I: Surface climate and atmospheric circulation, Part II: The oceanic heat budget (Madison, Wisconsin, USA: The Univ. of Wisconsin Press.)

Murty V S N, Ramesh Babu V, Rao L V G, Prabhu C V and Tilvi V 2000 Diurnal variability of upper ocean temperature in the southern Bay of Bengal during OctoberNovember, 1998 (BOBMEX-Pilot); Proc. Indian Acad. Sci. (Earth Planet. Sci.) 109, 2 267-277

Paul D K, Mujumdar V R, Puranik P V, Ghanekar S P, Deshpande V R, and Sikka D R 1990 Fluctuations of regional scale atmospheric features in relation to monsoon activities; Mausam 41, 2 309-314

Paul D K, Bhide U V, Ghanekar S P and Sikka D R 1992 Variability of sea surface temperature over the Arabian Sea and organised convection over Indian region during summer monsoon; Oceanography of the Indian Ocean, (ed) B N Desai 627-635

Rao R R, Raman K V S, Rao D S and Joseph M X 1985 Surface heat budget estimates at selected areas of north Indian Ocean during Monsoon-77; Mausam 36, 1 $21-32$

Sam N V, Mohanty U C and Satyanarayana A N V 2000 Conserved variable analysis of the marine boundary layer and air-sea exchange processes using BOBMEX-pilot data sets; Proc. Indian Acad. Sci. (Earth Planet. Sci.) 109, 2 305-314

Sarma Y V B, Seetaramayya P, Murty V S N and Rao D P 1997 Influence of the monsoon trough on air-sea interaction in the Head of the Bay of Bengal during the southwest monsoon of 1990 (Monsoon Trough Boundary Layer Experiment-90); Boundary-layer Meteor $\mathbf{8 2}$ $517-526$

Shukla J 1975 Effect of Arabian Sea-surface temperature anomaly on indian summer monsoon: A numerical experiment with the GFDL model; J. Atmos. Sci. 32, 3 503511

Sikka D R 1980 Some aspects of the large scale fluctuations of summer monsoon rainfall over India in relation to fluctuations in the planetary and regional scale circulation parameters; Proc. Indian Acad. Sci. (Earth Planet. Sci.) 89, 2 179-195

Stevenson J W 1982 Computation of heat and momentum fluxes at the sea surface during Hawaii-to Tahiti Shuttle Experiment; Hawaii Inst. Geophys. Rep. HIG-82-4 